REVISTA DE DERECHO UNED, NÚM. 11, 2012

\title{
LA EJECUCIÓN DE SENTENCIAS DINERARIAS EN LAS PARTIDAS
}

\author{
ENFORCEMENT OF MONETARY JUDGMENTS \\ IN VII PARTIDAS
}

\author{
Adolfo A. Díaz-Bautista Cremades \\ Profesor Asociado Universidad de Murcia \\ adiaz-bautista@um.es
}

Resumen: Las VII Partidas es la mayor obra legislativa del Derecho Común. En ellas se recoge, en lengua española, los principales preceptos recibidos del Derecho Romano y del Canónico conformando un corpus que resultaría de aplicación normativa hasta la promulgación del Código Civil en 1889. El objeto de este trabajo es analizar las consideraciones de las Partidas en relación con la ejecución de sentencias dinerarias y la comparación de las mismas con la regulación del pignus in causa iudicati captum establecido por Antonino Pío, en el proceso romano. La consideración de la Glosa de Gregorio López permite analizar las reflexiones que, en su día, ocasionaron las disposiciones alfonsinas al respecto.

Palabras clave: Partidas, ius commune, ejecución, embargo, subasta, almoneda, tercería.

Abstract: The "VII Partidas» called code, is the greatest legislative work of the ius commune. In them is collected, in Spanish language, the main precepts received from Roman and Canonical law forming a corpus that would result from regulatory application until the promulgation of the Civil Code in 1889. The object of this work is to analyse the considerations of items relating to the enforcement of monetary judgments and comparing them with the regulation of the pignus in causa iudicati captum established by Antoninus Pius for the Roman 
process. Consideration of the Glossae of Gregorio López analyzes reflections which, in his day, caused by the Alfonso's Code.

Keywords: Partidas, ius commune, enforcement, execution, pledge, auction, third-party-proceedings.

Recepción original: 16/10/2012

Aceptación original: 19/10/2012

Nuestro interés por la ejecución de sentencias en el Derecho común surgió a raíz del trabajo realizado, como tesis doctoral, sobre el pignus in causa iudicati captum en el procedimiento de la extraordinaria cognitio romana. Dicho estudio ${ }^{1}$, analiza con detalle las respuestas de la jurisprudencia y las constituciones imperiales a las cuestiones que planteó tal institución. Como consecuencia de aquel análisis, nos proponemos ahora considerar la recepción de la tradición romana sobre este tema en una obra tan señera del ius commune como las Partidas alfonsinas ${ }^{2}$.

Las XII Tablas establecían la ejecución personal del deudor, como medio de cumplimiento de las obligaciones dinerarias, mientras que en el proceso per formulas recaía la ejecución patrimonial sobre el patrimonio total del deudor ${ }^{3}$. En el procedimiento de la extraordinaria cognitio ${ }^{4}$ surgió el pignus in causa iudicati captum que suponía la apropiación de bienes singulares del deudor en ejecución de sentencias dinerarias para compeler al deudor al pago de las mismas o, en su caso, para su venta en pública subasta y, con su producto, hacer pago al acreedor. Aunque ya el proceso formulario conoció,

${ }^{1}$ Tesis doctoral presentada en la Universidad de Murcia el día 22 de junio de 2012 bajo el título "El embargo ejecutivo en la extraordinaria cognitio (pignus in causa iudicati captum)». Publicada, bajo licencia creative commons, por la Universidad de Murcia, en formato electrónico (visitado 25/11/2012) http://hdl.handle.net/10201/27996

${ }^{2}$ Hemos utilizado la Edición de 1555 de Andrea de Portonaris, con las Glosas de Gregorio López, reproducida en facsímil por el Boletín Oficial del Estado en 1985.

${ }^{3}$ BETTI E. v. «Condanna (diritto romano)», en NNDI, págs.1081-1084, Torino, 1959; LONGO G.E., v. «Esecuzione forzata (diritto romano)», ibid. t. VI, págs. 713 722, Torino, 1960, VOCI P., v. "Esecuzione forzata» (Diritto romano), en Enciclopedia del diritto, t. XV, págs. 422-430, Milano, 1966. ABELLÁN M. «Sententia» y «res iudicata». Conceptos romanos y evolución posterior, en Estudios J. Iglesias, t. I, págs. 1-11, Madrid, 1988.

${ }^{4}$ Como señala Fernández de Buján, por contraste con el proceso per formulas propio de la República: El proceso en el Imperio fue, por contraste, predominantemente escrito, lento, lleno de cautelas, de garantías procesales, de posibilidades dilatorias, de tecnicismos, de sutilezas jurídicas, y de reforzamiento del papel activo del magistrado como conductor del proceso, al tiempo que se le atribuye al propio magistrado, como profesional del derecho y funcionario de la Administración Pública, la competencia para dictar sentencia. Fernández de Buján, A.: Conflicto, controversia, contraposición, contienda, polémica, oposición: proceso y litigio, en Revista General de Derecho Romano, 18(2012), Iustel RI §412191. 
de manera excepcional, ciertos supuestos de ejecución sobre bienes singulares, el pignus in causa iudicati captum, que ha llegado a los ordenamientos modernos sin grandes cambios sustanciales, se generalizó en la práctica procesal romana por un rescripto de Antonino Pío referido por Ulpiano ${ }^{5}$ y Calístrato ${ }^{6}$.

El sistema de ejecución introducido por Antonino Pío perduró más allá de la caída del Imperio de Occidente, aplicándose -con algunas variaciones y localismos- en la Alta Edad Media. El Liber Iudiciorum, 5.6.5 contiene una ley de Chindasvinto en la que regula la ejecución «concursal para el caso de múltiples acreedores. Es interesante subrayar qu la norma está ubicada en el título VI del quinto Libro, dedicado a De pignoribus et debitis. El texto parece asumir el embargo patrimonial como medio normal de ejecución de sentencias de carácter patrimonial, no sólo dinerarias ${ }^{7}$, aunque -por estar destinado a regular la ejecución concursal- da por hecho el carácter universal y no singular de la ejecución, acercándose más a la actio iudicati ${ }^{8}$ del proceso per formulas que al pignus in causa iudicati captum. De hecho, la citada ley establece, para el caso de insolvencia del deudor, su entrega a los acreedores como esclavo, reviviendo -quizás- el enigmático nexum de que hablan algunas fuentes primitivas romanas. Probablemente su aplicación se vería alterada, en ocasiones, por la reaparición de la ejecución personal, nunca totalmente desterrada en Roma, y que reaparece, a lo largo de la historia, en épocas de crisis económica o social ${ }^{9}$.

Con la Recepción era inevitable que el pignus in causa iudicati captum romano volviese a ocupar un lugar relevante en la atención de los juristas. Sin embargo, las Partidas, la obra cumbre del ius commune en nuestra Patria, a diferencia de lo que sucede con otras instituciones, no tratan de manera exhaustiva la ejecución dinera-

${ }^{5}$ Ulp. 3, de off. cons D.42.1.15.

${ }^{6}$ Call. II cogn. D. 42.1.31.

7 ...ipsi nihilominus aut iuxta qualitatem debiti satisfacere compellendus est, vel damnandus a iudice.

${ }^{8}$ Como afirma Pérez Alvarez, la ejecución de sentencia en el proceso per formulas era un "expediente de naturaleza pretoria de carácter universal (pues comprende todo el patrimonio del deudor) y, cuando hay pluralidad de acreedores, colectivo, que consiste en la toma de posesión de todo el patrimonio del sujeto pasivo, decretada por el magistrado a petición de uno o varios acreedores», Pérez Álvarez, MP.: fase apud iudicem en el procedimiento formulario. ejecución de sentencia, en «Base de Conocimiento» RI $\$ 911261$, Iustel. Publicación electrónica consultada el 25/11/2012.

(http://www.iustel.com/v2/c.asp? $\mathrm{r}=911261 \& \mathrm{~s}=21 \& \mathrm{p}=5 . \& \mathrm{Z}=4 \& \mathrm{O}=1 \&$ sector $=$ )

${ }^{9} \mathrm{La}$ prisión por deudas es un atavismo que nunca ha desaparecido del todo a lo largo de la Historia, y que resurge en momentos de crisis económica, acompañando a la degradación del Derecho y de los valores morales. Supone una sobreprotección de la posición del acreedor, confundiéndose las esferas pública y privada del Derecho. 
ria. Las seis leyes que componen el título 3.27 apenas enuncian los principales problemas que se derivan del embargo ejecutivo, dejando para los comentaristas el desarrollo de los mismos ${ }^{10}$.

Tras examinar en los títulos anteriores las condiciones que deben reunir los juicios valederos, refiriéndose tanto a la validez intrínseca de la sentencia como a su firmeza, el Rey Sabio advierte en Part. 3.27.2 del deber de los condenados en juicio de cumplir voluntariamente el fallo en sus propios términos:

En tanta quantia o en aquellas cosas que señaladamente son puestas en el juicio.

Tal cumplimiento voluntario debe realizarse:

... Ulanamente, sin agravamiento et con buenas palabras.

Sólo si el condenado permaneciera rebelde, negándose a cumplir la condena:

Entonces deben los judgadores ayuntar homes armados et venir con ellos al logar, et cumplir su juicio poderosamente, de manera que la justicia venza.

La ejecución forzosa se reserva, pues, como último recurso para los casos en que el condenado se niegue al cumplimiento voluntario, como expresa el resumen que Gregorio López inserta al inicio de las glosas de esta ley (Part. 3.27.2).

Contra resistentes executioni sententiae quae iam transivit in rem iudicatam: veniat iudex manu armata ad exequendum, hoc dicit.

La moderna doctrina distingue entre la ejecución dineraria, la de condenas de dar cosas específicas o genéricas y la de hacer (genérico y personalísimo) o no hacer. Sin embargo, aunque la LEC establece

${ }^{10}$ Contrasta ello con el detalle y la profusión con que la institución es tratada en la compilación justinianea. En el Digesto encontramos referencias entre los sesenta y cuatro fragmentos contenidos en el tít. 1 del libro 42 (De re iudicata et de effectu sententiarum et de interlocutionibus). En el Código se hallan tres títulos relativos a la ejecución de sentencias: C.7.53 (De exsecutione rei iudicatae), C. 8.22 (Si in causa iudicati pignus captum est) y C.4.15 (Quando fiscus vel privatus debitoris sui debitores exigere potest), el segundo de los cuales contiene la regulación de nuestra institución. Formalmente, el primero de los títulos es el más extenso (contiene nueve constituciones) frente al segundo que sólo recoge tres; el tercero, sobre el ejercicio subrogado de las acciones del deudor, contiene cuatro rescriptos. También aparecen fuentes postclásicas que se refieren al embargo judicial, como las Pauli Sententiae (PS.5.5.4, en el título 5.5, De effectu sententiarum et finibus litium), así como en el Código Teodosiano (C.Th. 2.30.1), el Edicto de Teodorico (131), y en la Lex Romana Burgundionum (14.1). 
medidas ejecutivas diferentes para cada una de las formas, todas ellas acaban reconduciéndose a la ejecución dineraria ${ }^{11}$.

Part. 3.27.5 describe las diferentes formas de ejecución, destacando en primer lugar la necesidad de llevar a cabo la ejecución in natura, del propio modo en que fue dictado el fallo ${ }^{12}$. Esta exigencia es una derivación del principio establecido en la ley 2, del mismo título, para el cumplimiento voluntario:

Et debe facer esto llanamente, sin agravamiento et con buenas palabras, entregando al vencedor contra el demandado o a sus herederos en tanta quantia o en aquellas cosas que señaladamente son puestas en el juicio.

Conforme a esta norma, afirma la ley 5 que la ejecución puede ser dineraria:

... Si el juicio fue dado en razón de debda...

O bien de condena de dar cosa determinada:

... sobre alguna cosa cierta que ome demandasse por suya...

O, finalmente, de hacer:

... E si la sentencia fuese dada contra el demandado en razón de alguna cosa que deviesse facer...

${ }^{11}$ Así el artículo 701.3 para las cosas específicas, el 702 para las cosas genéricas, el 706 para obligaciones de hacer no personalísimo, el 709 para obligaciones de hacer personalísimo y el 710 para obligaciones de no hacer. En todos los casos cabe la posibilidad de reconducir la ejecución a la satisfacción pecuniaria al acreedor mediante el embargo de bienes.

${ }^{12}$ Ya en la cognitio extraordinaria se había admitido la ejecución in natura, como señala García Sánchez: Si la ejecución ha sido solicitada por un solo acreedor y se refiere a una cosa concreta, el magistrado ordena a sus funcionarios subalternos que procedan manu militari a la entrega de la res al demandante con el título que figura en la sentencia, pudiendo ser una adiudicatio. Si no es posible, porque la cosa ha sido destruida o no está en el patrimonio del vencido, entonces se transforma en una cantidad de dinero, cuyo monto se fija por el demandante mediante juramento, atendiendo al valor del objeto litigioso. Si se trata de entregar una suma de dinero se procede a la aprehensión de bienes del patrimonio del deudor vencido, que garanticen el pago, preferentemente bienes muebles (pignus in causa iudicati captum). Si el deudor no rescata los bienes embargados en el plazo de dos meses, pagando la condena, se venden en pública subasta y el actor se cobra con el dinero logrado, pasando el sobrante al deudor. Si no aparece postor en la subasta, el acreedor podía convertirse en adjudicatario o solicitar del magistrado que la cosa le fuera entregada en pago de lo que se le debía (impetratio dominii), no conservando entonces derecho alguno frente al deudor. García Sánchez, J.: Cognitio Extraordinaria, en «Base de Conocimiento, RI §910816», Iustel, publicación electrónica consultada el 25/11/2012, en:

http://www.iustel.com/v2/c.asp?r=910816\&s=21\&p=5.\&Z=4\&O=1\&sector= 
No se distingue, en cambio, entre el hacer genérico (en el que cabe ejecución subsidiaria) y el llamado «hacer personalísimo, en el que la prestación sólo puede ser realizada por el condenado. Tampoco hay referencia a las condenas de no hacer.

Por su parte, Part. 3.27.3 aclara, in fine, que el sistema de toma de prendas sólo se aplicará:

... E todas estas cosas que diximos fasta aquí en esta ley, han lugar en los juyzios que fuessen dados por razón de debda que deviesse el vencido, o por otra cosa que fuese tenido de fazer...

Mientras que en las condenas de dar cosa específica, sea mueble o inmueble, continúa el texto:

... Mas quando el juyzio fuesse dado sobre cosa cierta, quier fuesse mueble, o rayz que ome demandasse por suya: estonce deven cumplir el juicio en aquella cosa mesma de qual natura quier que sea.

Aunque la ley parece limitar la ejecución específica a las conenas dimanantes de acciones reales reivindicatorias (... sobre cosa cierta... que ome demandasse por suya... $)^{13}$ parece que se entenderían incluidos también aquellos supuestos en que se condenase al demandado a entregar cosa cierta y determinada en virtud de una acción personal.

Debe por tanto entenderse que las condenas a dar cosa genérica, distinta del dinero, se ejecutaban como debdas, embargando bienes para cubrir el coste de su adquisición. Del mismo modo las sentencias de hacer (se entiende de hacer genérico) se valorarían y se ejecutaría el patrimonio del deudor para abonar el coste de la ejecución subsidiaria.

Part. 3.27.4 trata de las situaciones en que una misma sentencia condena a varias personas a una misma prestación. Cabe pensar que, en estos casos, querría el acreedor suponer una relación de solidaridad entre todos los condenados, bien porque ya fueran solidarios en la obligación de que trajo causa la sentencia, o bien porque la condena derivase de un mismo título. Sin embargo las Partidas parecen querer poner coto a dicha pretensión, en protección de los deudores, estableciendo la mancomunidad como sistema general, de modo que la solidaridad sólo puede derivarse de la literalidad de la condena ${ }^{14}$. A este respecto señala el Rey Sabio que:

${ }^{13}$ La glosa $k$ de Gregorio López a esta frase remite a la reivindicatio.

${ }^{14}$ La traducción de Gregorio López reza así: Si plures una sententia condemnentur ad aliquid dandum, vel faciendum in solidum, potest fieri executio in bonis omnium, vel cuiuslibet: sed si non aditur quilibet in solidum non fiet executio, nisi in bonis omnium cuilibet pro parte sua per capita computanda, etiam si primo erant quilibet in 
Acaesce a las vegadas que dan sentencia contra muchos omes sobre alguna cosa que deven dar, o fazer condenandolos que la paguen o la fagan. E porende dezimos, que si el judgador que diere tal sentencia como esta condenare señaladamente a cada uno dellos por todo, que se pueda cumplir la sentencia en los bienes de cada uno dellos.

Pero que en caso contrario, es decir si el Juez no ha declarado a cada uno de los condenados como responsable por el total de la condena,

E si ciertamente non fuesse dada condenando a uno por todo: Estonce dezimos que se debe complir en los bienes de todos comunalmente, pagandolo todos por cabezas, ...

E incluso, insiste la misma ley en que:

... e non pueden apremiar a ninguno dellos por todo quando la sentencia fuere assi dada, maguer se oviesse obligado cada uno por todo, a la sazon que entraron fiadores o debdores de so uno.

La posibilidad, ciertamente anómala, de que una sentencia condenase mancomunadamente a co-deudores o co-fiadores que se constituyeron como solidarios, aparte de presuponer un amplio arbitrio judicial, subraya la sustitución de la deuda inicial, por la nacida de la sentencia, es decir, la «novación necesaria operada por el iudicatum, sin que las circunstancias extraprocesales de la obligación, que no hubieren sido recogidas por la Sentencia, puedan afectar a la ejecución.

La tradición romana marcaba la necesidad de conferir un plazo al ejecutado, para que pudiera cumplir voluntariamente la sentencia antes de que el actor triunfante pudiera instar la ejecución ${ }^{15}$, como ocurre en la actualidad de acuerdo con el artículo 548 LEC. Para tal

solidum obligati. Hoc dicit. El artículo 1137 CC. recogió este principio: La concurrencia de dos o más acreedores o de dos o más deudores en una sola obligación no implica que cada uno de aquéllos tenga derecho a pedir, ni cada uno de éstos deba prestar integramente las cosas objeto de la misma. Sólo habrá lugar a esto cuando la obligación expresamente lo determine, constituyéndose con el carácter de solidaria.

${ }^{15}$ XII T. 3: Aeris confessi rebusque iure iudicatis XXX dies iusti sunto. En Derecho clásico el juez podía conceder un plazo discrecional al condenado para que cumpliera voluntariamente la sentencia, si éste lo pedía (Call. 2 cogn. D.42.1.31). Esta discrecionalidad del juzgador para conceder o alargar el plazo del condenado para pagar, y evitar así la ejecución, desapareció en el Derecho postclásico según una ley de Graciano, Valentiniano y Teodosio, del año 380, que conocemos a través de CTh.4.19.1pr. (=Brev.4.17.1pr.). Este término bimestral fue ampliado a cuatro meses por Justiniano (C.7.54.2, del 529), cuando dispuso que aquellos que, habiendo sido condenados hubiesen, demorado más de cuatro meses, a contar desde el día de la condena, o, si hubiesen interpuesto apelación, desde el día de la confirmación de la 
cumplimiento voluntario, cuya omisión justifica la ejecución forzosa, señala la Part. 3.27.5 un plazo de diez días en caso de condenas dinerarias:

... si el juyzio fue dado en razón de debda que el demandado conosciesse o fuesse vencido della delante el judgador, deven lo cumplir en los sus bienes fasta diez dias ${ }^{16}$.

No se establece el mismo plazo para el condenado a dar cosa específica, que debe:

... E si por aventura fuesse dado sobre alguna cosa cierta que ome demandasse por suya: estonce debe se cumplir luego en aquella cosa sobre que fue dado el juyzio: ...

Aunque cabe que el ejecutado solicite al juez un plazo para el cumplimiento, para lo cual debe ofrecer fiadores, como establece esta ley:

... e si el condenado dixesse que non podria fazer luego entrega della, porque es en otra parte, si esto non dixesse maliciosamente, deve dar buenos fiadores, que a aquel plazo que el judgador tuviere por guisado, que dé aquella cosa o aquello por que fuere apreciada, si non la pudiesse aver.

Por su parte, en las condenas de hacer, parece que el cumplimiento debe ser inmediato:

E si la sentencia fuesse dada contra el demandado en razón de alguna cosa que deviesse fazer, debe lo apremiar que la faga, assi como fue puesto o lo prometió. ${ }^{17}$

En el comienzo de esta ley 5, se determinan los requisitos para que la sentencia sea ejecutiva:

sentencia, deberían pagar las cantidades dispuestas en la misma, con el interés del uno por ciento.

${ }^{16}$ Gregorio López: advierte Nota bene, quia in iure communi antiquo erant duo menses... (glosa d)

${ }^{17}$ Concluye la ley refiriéndose a las causa criminales: ... e si el juyzio fuesse dado sobre algund pleyto de escarmiento de justicia de muerte, o de perdimiento de miembro, debe se luego cumplir de dia concejeramente ante los omes, e non de noche a furto. Ca la justicia non tan solamente debe ser cumplida en los omes por los yerros que fazen: mas aun porque los que la vieren tomen ende miedo, e escarmiento para guardarse de fazer cosa, porque merezcan recebir otro tal. Puntualiza Gregorio López que hay que entender "luego" en el sentido del momento en que la sentencia constituye cosa juzga$d a$, por haber transcurrido el tiempo para la apelación. Intellige potest quando transivit sententia in rem iudicatam: qua lapsum est tempus appellandi..., (glosa h). 
Seyendo el juyzio valedero, de manera que se deve cumplir, porque alçada non tomaron del, o si fue tomada que confirmaron la sentencia assi que non ha y mas alçada:...

Es decir, es precisa una sentencia condenatoria firme que no adolezca de vicios intrínsecos. En ello insiste el Rey Sabio en toda la regulación al referirse a juicios valederos, pues -como dice Ulpiano (D.42.1.4.6) - si por alguna razón no fuese válida la sentencia no se puede hablar de condena ${ }^{18}$ :

Tanto la ley 2 (.... si aquel que es vencido otorgó la debda por sí: o le fue probado de guisa que non lo pueda contradecir...) como la ley 5 (... si el juicio fue dado en razón de debda que el demandado conosciesse o fuese vencido della delante el judgador...) dan a entender que la ejecución dineraria por toma de prendas podía abrirse tanto por sentencia que recogiesea tal condena, como por confesión, al igual que en el Derecho Romano ${ }^{19}$. No menciona, sin embargo, el Rey Sabio, otras posibles formas de ficta condena como son el juramento decisorio ${ }^{20}$, ni la indefensión, las cuales, probablemente, conducirían al dictado de una sentencia de condena. ${ }^{21}$

Part. 3.27.1 se encarga de determinar la competencia en el proceso ejecutivo. El Rey mantiene el criterio, ya establecido en la extraordinaria cognitio ${ }^{22}$, de atribuir la competencia al mismo órgano judicial que dictó la sentencia:

Cumplir pueden los juyzios que son valederos aquellos mismos judgadores que los dieron. Esso mismo pueden fazer los mayorales dellos ${ }^{23}$.

${ }^{18}$ Ulp. 58 ad ed. D.42.1.4.6: Si aliqua ratione sententia nullius momenti sit, dicendum est condemnationis verbum non tenere.

${ }^{19}$ Como recoge Calístrato en D.42.1.31, his, qui fatebuntur debere aut ex re iudicata necesse habebunt reddere,... eorum, ...qui... non reddiderint, pignora capi... Vid. DI PAOLA, S.: Confessio in iure Catania-Milano, Giuffrè, 1952; CHIAZZESE L., Jusiurandum in litem, Milano, Giuffrè, 1958; SCAPINI N., La confessione nel diritto romano. I. Diritto classico. Torino, Giappichelli, 1973; Sobre la confesión del crédito vid. LITEWSKI W. "Confessio in iure» e "sententia», en Labeo 22(1976) págs. 252267, SCAPINI N., La confessione nel diritto romano. II. Diritto giustinianeo Milano, Giuffrè, 1983.

${ }^{20}$ Ya desaparecido mucho tiempo atrás

${ }^{21}$ Lo mismo ocurría, al parecer, en la extraordinaria cognitio. Vid, LITEWSKI, W.: Pignus in causa iudicati captum, SDHI 40 (1974). pág. 270, n. 269.

${ }^{22}$ Ulp. 3 de off. cons. D.42.1.15 pr: ...ut iudicum a se datorum vel arbitrorum sententiam exsequantur hi qui eos dederunt...

${ }^{23}$ Dice a propósito de esto, Gregorio López, que se deriva de ello que tienen competencia para ejecutar quienes, conforme al derecho ordinario, pueden dictar sen- 
Tal criterio supone considerar la ejecución, no como un nuevo proceso, sino como un apéndice del declarativo, como ocurría en el sistema cognitorio, a diferencia del formulario. Ello no impide que el juez que dictó la sentencia, y que ordena la ejecución, se valga del auxilio de otros jueces que, por el lugar donde radiquen los bienes objeto de apremio, tengan competencia sobre ellos:

E otrosi dezimos, que si el juicio fuere dado en un lugar, e la cosa que judgaron es en otro, que el juez en cuyo lugar es, debe cumplir la sentencia entregando la cosa al vencedor, después que hobiere rescebido carta del que dio la sentencia sobre ello. Esso mismo dezimos que debe ser guardado quando el judgador diesse la sentencia en razón, de debda que alguno deviesse, cuyos bienes fuessen en otro lugar, e non en aquel do dieron el juicio. ${ }^{24}$

Cuestión diferente de este auxilio judicial, entre órganos de diferente competencia territorial, es la posibilidad de que el juez que decrete la ejecución se haga valer de auxiliares para realizar los necesarios actos en que se concreta el apremio ${ }^{25}$. Lo dice así Part. 3.27.1:

E non tan solamente los juezes pueden por si cumplir los juizios que son valederos. Mas los pueden fazer cumplir por sus omes que tengan señalados para esto, o por la justicia, o por el merino del lugar a quien lo mandassen.

El establecimiento de un orden para proceder al embargo y venta de los bienes, en cualquier época, está presidido por una doble finalidad: hacer esta medida extrema lo menos gravosa posible al ejecutado y, al mismo tiempo, facilitar su realización económica para satisfacer, de la mejor manera posible, el interés del ejecutante ${ }^{26}$. El rescripto del emperador Antonino Pío que estableció el sistema general de embargos ejecutivos, prescribía que se procediese en primer

tencias y se plantea, en caso de haberse producido apelación, quién será competente para la ejecución, si el juez a quo o el órgano ad quem se tramitó la alzada.

${ }^{24}$ Gregorio López: Sententiam potest exequi iudex qui eam protulit vel eius maior per se vel per suos executores. Sed si alterius territorio sint bona condemnati, aut res de qua est pronuntiatum, debet iudex illius territorio ad litteram iudicantis sententiam executioni mandare...

${ }^{25}$ También en la extraordinaria cognitio se autorizaba al juez ejecutor a servirse de executores dati y apparitores. En nuestra opinión no existen suficientes datos para señalar nítidamente la diferencia entre ambas figuras, como se ha sostenido.

${ }^{26} \mathrm{El}$ artículo 592 LEC establece como primer criterio para determinar el orden de proceder en los embargos el acuerdo entre las partes y en su defecto el criterio del Secretario judicial valorando la mayor facilidad de su enajenación y la menor onerosidad de ésta para el ejecutado. Sólo subsidiariamente se establece un orden específico para proceder (dinero, bienes y créditos de muy fácil realización, bienes muebles, inmuebles, salarios y otros créditos). 
lugar sobre los bienes muebles, luego sobre los fundos y, sólo a falta de éstos (quizás por innovación de Caracalla) se ejecutarán los derechos reales (iura) y personales (nomina) del deudor ${ }^{27}$.

Dicho orden parece justificarse en que, en una economía fundamentalmente agraria, le es más fácil al deudor desprenderse de los bienes muebles que de los inmuebles ${ }^{28}$, que constituyen la base de su economía familiar. Lo cierto es que la misma regulación trascendió al código de las VII Partidas ${ }^{29}$ y llegó, con ligeros cambios, hasta nuestros días.

Tras establecer Part. 3.27.3 el principio de responsabilidad patrimonial universal:

En las cosas et en los bienes del dueño del pleyto contra quien es dado el juyzio, se debe mandar cumplir, e fazer la entrega,... bles:

El Rey Sabio ordena que se tomen en primer lugar las cosas mue-

... primeramente tomando delas cosas que fueren muebles: tantas en que se pueda cumplir, e pagar la quantia de la debda que es puesta en la sentencia,...

Sólo si los muebles no bastasen para cubrir la responsabilidad del deudor, continúa el texto, ordenando la toma de inmuebles:

.... si el mueble non abondasse deben tomar delas cosas que son rayz tantas que cumplan.

Se pregunta Gregorio López qué sucedería si el deudor prefiriese que se embargasen los inmuebles y no los muebles ${ }^{30}$ y opina que «quizá (forte) no proceda aplicar esta ley que exige que se tomen en primer lugar los muebles ${ }^{31}$ porque esto se introdujo a favor del deudor. ${ }^{32}$

${ }^{27}$ Ulp. 3 de off. cons. D.42.1.15.2.

${ }^{28}$ Abona esta interpretación, de que el orden de proceder en los embargos se instituye principalmente en favor del deudor, lo que afirma Gregorio López, vid infra, quia hoc est introductum favore debitoris.

${ }^{29}$ Gregorio López: en su glosa a Part. 3.27 .3 señala, siguiendo a Bártolo: Et si iste ordo non servaretur posset appellare debitor, sed si non appellaret processus teneret ... cuius opinio est magis communis.

${ }^{30}$ Glosa a Part. 3.27.3: Quid si debitor vult quam capiantur bona soli et non mobilia: an tunc debeat servari quod hic dicitur?

${ }^{31}$... forte tunc non proceeret ista lex exigens ordinem in capiendo prius mobilia:

32 ... quia hoc est introductum favore debitoris... 
Nada menciona el texto alfonsino sobre los derechos reales, pasando, tras los bienes inmuebles, al embargo de los créditos:

E quando todo esto non cumpliesse para fazer la entrega, deven entregar al vencedor delas debdas manifiestas que deven al vencido, fasta que se cumpla la quantia de la sentencia.

Surge la duda, al analizar esta ley, de qué se considera «deuda manifiesta». Cabe pensar que sólo aquellas deudas expresamente reconocidas por el deudor, de manera judicial o quizás extrajudicial, podían ser embargadas ${ }^{33}$. Sin embargo también es posible suponer que bastara para considerar una deuda "manifiesta» el hecho de que no hubiera sido negada o contradicha por el deudor, debiéndose precisar entonces si bastaba una mera negativa o reticencia al pago para hacer el crédito inembargable o era precisa una oposición procesal del deudor ${ }^{34}$.

${ }^{33}$ Gregorio López remite a D.42.1.15.9, Sed utrum...

${ }^{34}$ En Derecho Romano se había optado por permitir tan sólo el embargo de créditos confesados, es decir de aquellos cuya aceptación por el deudor constase y fuesen, por tanto, ejecutables sin discusión alguna. Lo señala Ulp. 3 de off. cons D.42.1.15.9, cuando se pregunta si se puede tomar solamente un crédito confesado, o también aquél en el que el deudor negare deber, y responde: es más cierto que se toma tan sólo el que ha sido confesado: Sed utrum confessum nomen tantum capi possit an etiam si neget quis se debere, videamus. et magis est, ut id dumtaxat capiatur, quod confitetur:.. El tema, sin embargo, debió ser discutido ya que Ulpiano se hace eco de la polémica, al decir que si algún deudor se opusiere, lo más justo será apartarse del crédito, es decir, no embargarlo, aunque "puede que alguno», siguiendo el ejemplo de lo que sucede con las prendas de bienes corporales, siguiere adelante y dijere que los mismos jueces que conocen sobre la propiedad, en caso de discusión sobre la titularidad de los bienes embargados, es decir, de la tercería, deben conocer también sobre el crédito. Pero, concluye, se resolvió lo contrario por rescripto, aunque no nos aclara cuál fue el rescripto que puso fin a la discusión, como tampoco qué opiniones jurisprudenciales mantenían la tesis rechazada: ...ceterum si negetur, aequissimum erit discedi a nomine, nisi forte quis exemplum secutus corporalium pignerum ultra processerit dixeritque ipsos debere iudices de nomine cognoscere, ut cognoscunt de proprietate: sed contra rescriptum est. Vid. Von der FECHT, W. R., Die Forderungspfändung im römischen Recht. Der Vollstreckungszugriff auf Forderungen im Rahmen des pignus in causa iudicati captum und des Fiskalrechts der römischen Kaiserzeit, Böhlau, Colonia, Weimar, Viena, 1999. pág. 95). Sospecha este autor que Ulpiano no quiso rechazar en D.42.1.15.9 de manera categórica la pignoración de créditos discutidos, sino señalar una tendencia, expresada fundamentalmente en el fragmento siguiente, donde recomienda que se actúe de la manera que parezca más fácil para ejecutar la sentencia. Apunta FLEISCHMANN. M Das pignus in causa iudicati captum, Koebner, Breslau, 1896, pág. 59) que podría darse la situación inconveniente de que, si un deudor negase el crédito, sin incurrir en fraude, tendría el acreedor que renunciar inmediatamente al crédito y tampoco podría incluirlo en un concurso. Concluye afirmando que esto fue modificado por Justiniano, en C.8.21.1, del 529. Ciertamente, el empleo de la palabra actio, en esta constitución, parece indicar que se podrían embargar los créditos aunque el deudor los discutiese, pero la redacción 
Tampoco se expresa el Rey Sabio sobre la especial consideración que siempre ha tenido el dinero en el orden de proceder en los embargos y que también tiene en la actualidad. ${ }^{35}$ En Derecho Romano, a pesar de la formulación general -casi idéntica a la de las Partidasque establece el orden tripartito de bienes muebles, inmuebles y derechos, estableció la Jurisprudencia que se tomara, con carácter previo al resto de bienes, no sólo el dinero que se hallare en poder del ejecutado, ya que se trataba de un bien mueble incluido por tanto en el primer escalón del orden, sino también el dinero ingresado en un banco como si estuviese en poder del condenado, es decir, como un bien mueble, tal como ocurre hoy día ${ }^{36}$. En Derecho Romano si el dinero estuviere en poder de los banqueros, solía ser tomado igualmente en prenda ${ }^{37}$, y también si estuviere en poder de otro cualquiera, pero destinado al condenado ${ }^{38}$.

Part. 3.27.3 contiene una detallada relación de bienes inembargables:

E non deben entregar por razón de debda sobre que fuese dado en juicio, en caballos, nin en armas de caballeros, nin en soldada, nin en tierra que fuese puesta para guisamiento dellos, nin en bueyes de arada, cuyos quier que sean, fallando otros bienes del vencido en que se pueda cumplir el juycio.

Por supuesto en Derecho moderno se considera parcialmente inembargable el salario ${ }^{39}$ del mismo modo que las herramientas, útiles profesionales y ropas y mobiliario del ejecutado ${ }^{40}$. Sin embargo ya en Derecho Romano se advierte una tendencia a declarar ciertos bienes inembargables. Caracalla advierte, en C.7.53.4 $4^{41}$ del 216, que el presidente de la provincia no consentirá que se embarguen las soldadas más que como úl-

no es tan tajante que permitiera afirmarlo, de manera rotunda, pues la formulación general de la embargabilidad de los créditos discutidos venía aceptada de antiguo.

${ }^{35}$ Art. 634 de la L.E.C.

${ }^{36}$ Art. 592 de la LEC.

${ }^{37}$ Vid. BETHMANN-HOLLWEG, Der römische Civilprozess, t. II, ed. Adolph Marcus, Bonn 1865, reimpresión facsímil Scientia Aalen, parág. 115, pág. 695,. KASER, M.: Das römische Privatrecht, erster Abschnit, Munich, 1971, parág. 126.II.

${ }^{38}$ Ulp. 3 de off. cons. D.42.1.15.11: Sed et si pecunia penes argentarios sit, aeque capi solet. hoc amplius et si penes alium quem, destinata tamen ei, qui condemnatus est, solet pignoris iure capi et converti in causam iudicati. Ulp. 3 de off. cons D.42.1.15.12 Praeterea pecuniam quoque depositam nomine condemnati... solent capere, ut iudicato satisfiat... La expresión «dinero depositado a nombre del condenado», es evidente que se refiere a la figura jurídica anómala del «depósito irregular».

${ }^{39}$ Art. 607 de la LEC.

40 Artículo 606.

${ }^{41}$ Stipendia retineri propterea, quod condemnatus es, non patietur praeses provinciae, cum rem iudicatam possit aliis rationibus exsequi. 
timo recurso, cuando la cosa juzgada no se pueda ejecutar de otro modo, lo que parece indicar que el embargo de estos estipendios militares debería ir después de la toma en prenda de los otros créditos indiscutidos.

Junto a ello, encontramos un caso excepcional de inembargabilidad de bienes muebles, en una ley de Constantino, C.8.16.7, del 315, que prohíbe tomar en prenda, en ejecución de sentencias civiles, los esclavos o los bueyes que aran o los aperos de labranza (...servos aratores aut boves aratorios aut instrumentum aratorium...), aunque la justificación de lo que podría parecer un precedente de la moderna inembargabilidad de los instrumentos de trabajo aparece en la norma constantiniana apoyada en un fundamento mucho menos «humanitario, pues no es otra que evitar que con el embargo se retrase el pago de los tributos (... ex quo tributorum illatio retardatur), es decir que el interés del Fisco se sobrepone al del particular ejecutante ${ }^{42}$. Esta regla aparece con una formulación mucho más escueta y general en una constitución de Honorio y Teodosio II, del año 414, recogida por los compiladores en C.8.16.8 $8^{43}$, que prohibía quitar, a causa de una prenda, algo que correspondiera al cultivo del campo y, como tal, llega al texto de las Partidas.

La propia Ley III comienza precisando que la ejecución se realizará sobre los bienes del ejecutado ${ }^{44}$. Ya el Derecho Romano se había encargado de precisar que los bienes objeto de embargo debían ser propiedad del ejecutado. Así lo subrayan un rescripto de Severo y Caracalla, del año 197, C.4.15.1 para las cosas del tutor, cuando se condena al pupilo ${ }^{45}$, una ley de Honorio y Teodosio, del 422, C.12.60.4 $4^{46}=$ CTh.8.8.10 y otra de Zenón, (474-491) C.11.57.1 ( $\sin$ fecha). No obstante, cabía siempre la posibilidad de que esto se realizase por error, o, negligencia del ejecutor o, incluso que un tercero, en connivencia con el ejecutado, alegase que el bien era suyo,

${ }^{42}$ Esta ley aparece en CTh.2.30.1 [=BREV.2.30.1], pero en lugar de una pena indeterminada, amenaza al contraventor con la pena capital. La interpretatio subraya el motivo fiscal: Multi pro fiscali debito servos cultores aut boves aratorios de possessionibus causa pignoris auferre praesumunt, de quorum laboribus tributa redduntur, et ideo si quis creditor vel curator pacis vel curialis aut quicumque* exactor hoc facere praesumpserit*, a provinciae indice puniatur.

${ }^{43}$ C. 8.16.8 Honor. et Theodos. (414). Pignorum gratia aliquid quod ad culturam agri pertinet auferri non convenit.

${ }^{44}$ En las cosas et en los bienes del dueño del pleito contra quien es dado el juicio, se debe mandar cumplir et facer la entrega...

${ }^{45}$ Propter aes alienum pupilli res tutoris, qui nihil ex bonis eius tenet, pignori capi non oportet. Vid. D.26.7.2pr.

${ }^{46}$ Nullam possessionem alterius pro alienis debitis publicis sive privatis praecipimus conveniri. 
para sustraerlo de la ejecución. Surgía entonces una controversia en la que alguien, distinto del ejecutado, mantuviera que los objetos embargados le pertenecían a él, o que tenía sobre dichos bienes un derecho preferente al del ejecutante. Es lo que hoy denominamos «tercerías y que deben ser resueltas en el curso del procedimiento ejecutivo ${ }^{47}$. Conviene tener presente que se trata de discusiones planteadas mientras se está tramitando la ejecución, es decir, cuando los bienes han sido trabados, pero aún no se ha procedido a su venta. Una vez vendidas las cosas tomadas en prenda cabe también que un tercero alegue derechos sobre ellas, pero la discusión será con el comprador, en un proceso diferente ${ }^{48}$.

Esta intervención de un extraño durante el procedimiento ejecutivo puede revestir dos modalidades diferentes: la, hoy llamada, «tercería de dominio en que el tercero afirma su propiedad sobre la cosa trabada y pretende que no se venda, sino que se levante el embargo sobre ella y se le entregue, y la denominada «tercería de mejor derecho en la lo que alega el tercerista su derecho preferente al del ejecutante y no pretende impedir la venta sino que, con el precio obtenido, se satisfaga su crédito, dejando al ejecutante el eventual superfluum.

Los textos romanos abordan el problema de las «tercerías. Ulp. 3 de off. cons. D.42.1.15.4 ${ }^{49}$, afirma que, según un rescripto de Caracalla, si existiera controversia sobre la propiedad de las cosas embargadas debían conocer sobre ella los mismos que ejecutaban la sentencia, en un juicio incidental y sumario, cuya resolución no prejuzgaba de manera definitiva la titularidad de la $\operatorname{cosa}^{50}$.

${ }^{47}$ Cap. III., Tít. IV, del Lib. III de la LEC.

${ }^{48}$ Vid. D.42.1.15.6-7 y C.Th.11.9.1, (Const.. 323).

${ }^{49} \mathrm{Si}$ rerum, quae pignoris iure captae sunt, controversia fiat, constitutum est ab imperatore nostro ipsos, qui rem iudicatam exsequuntur, cognoscere debere de proprietate: et si cognoverint eius fuisse qui condemnatus est, rem iudicatam exsequentur. sed sciendum est summatim eos cognoscere debere nec sententiam eorum posse debitori praeiudicare, si forte hi dimittendam eam rem putaverint, quasi eius sit, qui controversiam movit, non eius, cuius nomine capta est. Sobre este fragmento se ensañó la literatura crítica. Vid. AVERSANO, N. Constitutio principis ed interpretazione giurisprudenziale in D.42.1.15.4: Un caso di opposizione di terzo ad esecuzione, en AG. 193 fasc. 1(1977) págs: 79-92. BESELER, G. Beiträge zur Kritikder römischen Rechtsquellen 1, Tübingen 1910, págs. 30 y sigs., DE MEDIO, A. I tribonianismi avvertiti da Antonio Fabro, en BIDR 13 (1900) pág. 235, LEVY, E. en ZS 46 (1926), reseña de los Studi in onore di Perozzi (1926), págs. 413-424, ARANGIO-RUIZ, V. Istituzioni di diritto romano, Nápoles 1967, pág. 157. KRÜGER, H.: Das summatim cognoscere und das klassische Recht, en ZS 45, 1925, págs. 71-72, SIMON, D. Summatim cognoscere. Zwölf Exegesen, en ZS. 83(1966) págs: 157-158.

${ }^{50}$ Art. 603 LEC. Vid. WACKE, A., Audiatur et altera pars. Zum rechtlichen Gehör im römischen Zivil- und Strafprozess, en Ars boni et aequi. Festschrift für W. Waldstein, Stuttgart 1993, pág. 385. KRÜGER, H., Op. cit. pág. 70-71. 
Cuando la discusión versaba sobre un derecho real de garantía que afectase los bienes embargados al pago de un crédito anterior ${ }^{51}$ por ejemplo otra prenda, o hipoteca, parece que se tomaría un pignus in causa iudicati sobre el objeto, aunque estuviese en poder de un acreedor pignoraticio del ejecutado ${ }^{52}$, respetando su derecho preferente a cobrar, una vez vendido en subasta.

También el Rey Sabio se hace eco de este problema, en Part. 3.27.3:

E si por aventura en cumpliendo el juycio acaesciese contienda sobre las cosas que tomaban para fazer la entrega, diziendo algunos que eran suyas, o que avian derecho en ellas, e non de aquel contra quien fue dada la sentencia: estonce deve e judgador llanamente saber verdad si es como dizen: e si fallare que es assi, deve dexar aquellas cosas, e cumplir el juyzio en las otras del vencido que fallare que son sin contienda.

Plantea el Rey Sabio aquí nítidamente las dos posibles «tercerías» analizadas más arriba, la de dominio y la de mejor derecho, disponiendo, como ya ocurría en Derecho Romano (y sucede en la actualidad) que sean resueltas tales contiendas por el propio juez de la ejecución. Aunque el tenor literal del texto alfonsino no establezca, de forma expresa, que este conocimiento tenga carácter sumario, se puede deducir de la palabra llanamente. También se puede afirmar que esta ley confirma, de modo implícito, la tradición romana, según la cual, la decisión judicial de la controversia, sólo tenía el efecto negativo de levantar el embargo sobre el bien, sin pronunciarse, de manera positiva, sobre la titularidad dominical del tercerista, pues se limita a disponer que, en caso de estimar el juez la pretensión del tercerista, ... deve dexar aquellas cosas, e cumplir el juyzio en las otras del vencido que fallare que son sin contienda.

Para Gregorio López la cuestión no ofrece dudas y en la glosa inicial de esta ley utiliza la expresión summatim cognoscere de D.42.1.15.4:

Et si tertius se opponat executioni afferens bona esse sua, vel ius in eis habere, iudex de hoc summatim cognoscet.

De lo que no nos informan ni esta ley de Partidas, ni las glosas de Gregorio López es sobre cómo se actuaría en la que hoy llamamos «tercería de mejor derecho», es decir sobre la aparición de un acreedor con un derecho preferente al del ejecutante sobre la cosa embargada. Tampoco, como ya hemos advertido, los textos romanos

${ }^{51}$ En Derecho actual no se ven afectados por el embargo posterior a su inscripción os derechos inscritos en el Registro de la Propiedad con prioridad sobre la anotación, de modo que hoy se refiere la tercería de mejor derecho a los privilegiados.

52 Vid. FLEISCHMANN, M. cit. pág.59. 
ofrecen una solución incontrovertible. Cabe pensar que el legislador de Partidas prefiriese que, en todo caso, «dejase la cosa» el juez de la ejecución, es decir, levantase el embargo, tan pronto como apreciase la veracidad de la pretensión del tercerista, tanto si era de dominio como de mejor derecho. Nos parece más razonable pensar que, tal como ocurre en la actualidad, y probablemente también el Derecho Romano, se siguiese adelante con la ejecución y, una vez realizado el valor del bien embargado, se pagase con su importe al tercerista acreedor preferente, dejando el superfluum para el ejecutante, y para el ejecutado, en su caso.

La finalidad del embargo, en todos los tiempos, es forzar al ejecutado para que pague la deuda reclamada, del mismo modo que la prenda convencional supone un acicate para que el deudor cumpla. Pero si finalmente la medida de aseguramiento no consigue su principal efecto, se hace necesario expropiar al deudor del bien afecto al pago y satisfacer el interés del acreedor.

El Rey Sabio contempla el apremio de los bienes embargados en Part. 3.27.6, bajo el epígrafe general de Como deven ser vendidos los bienes que fueren tomados a alguno, por razon de entrega o de juyzio:

Entregado seyendo algún ome en los bienes de su debdor por sentencia del juez, si el debdor non pagasse lo que avia de dar, puede meter en almoneda aquella cosa que le entregaren, con otorgamiento del judgador, e almonedear la fasta veynte días, e de si debe se vender al que mas diere por ella de los veynte dias en adelante. E si por aventura mas valiesse que la debda que avia a recebir, lo demás debe lo dar al que era señor de la cosa. E si valiesse menos debe el judgador aun, entregar en los bienes del vencido aquello que valia de menos ...

Comparando esta ley con la tradición del Derecho Romano, se observa que no aparece en esta ley alusión al plazo de dos meses que debía mediar entre el embargo y la prenda, según Call. 2 cog. D.41.1.31 y CTh. 11.9.1 (Const. 323).

La expresión utilizada por el texto para prescribir la subasta de los bienes al disponer que el juzgador "puede» meter en almoneda aquella cosa, parece dejar la puerta abierta a la posibilidad de que no siempre debiera procederse a la realización de los bienes. La subasta sería una opción para el juez, que también podría admitir el acuerdo entre ejecutante y ejecutado, conducente a la adjudicación directa de la cosa al primero, o la venta a un comprador determinado. Curiosamente esta posibilidad concuerda con cierta vacilación que encontramos en los textos romanos al respecto, pues un rescripto 
de Alejandro Severo del 223, C.8.22.2pr. nos señala que así «suele (solet) hacerse ${ }^{53}$, y otro de Gordiano, del año 239, colocado por los compiladores a continuación del anterior, C.8.22.3, apunta que era costumbre (consuerunt) que las prendas tomadas por autoridad del presidente como consecuencia de la sentencia se vendiesen preferiblemente y no se poseyeran por el ejecutante a título de dueño ${ }^{54}$. De cualquier modo, tanto de la redacción de la ley alfonsina, como de los textos romanos, parece desprenderse que el normalmente el embargo conduciría a la subasta de los bienes.

Sobre la subasta ofrece pocos datos la ley Part. 3.27.6, pues tan sólo dispone que se ofrecerán los bienes durante veinte días, adjudicándose al mejor postor (...almonedear la fasta veynte días, et desi débese vender al que mas diere por ella de los veynte dias adelante ...)

Actualmente se establece, en las subastas de bienes embargados, un precio mínimo de salida, para evitar que la venta se realice por un precio muy inferior al valor del bien ${ }^{55}$. No tenemos datos sobre si en Derecho Romano, se establecía una valoración previa de los bienes embargados, y un límite mínimo para las ofertas. Sin embargo, aparecen en las fuentes romanas numerosos datos que nos llevan a pensar que el precio fijado para la venta debía aproximarse al valor real ${ }^{56}$, de acuerdo con la idea de iustum pretium en la compraventa ${ }^{57}$, pero este pasaje de las Partidas no contiene referencia alguna a esta cuestión.

${ }^{53} \mathrm{Cum}$ in causa iudicati aliqua res pignori capitur, per officium eius qui ita decrevit venumdari solet, non per eum, qui iudicatum fieri postulavit.

${ }^{54}$ In causa iudicati pignora ex auctoritate praesidis capta potius distrahi quam iure dominii possideri consuerunt... En las deudas fiscales parece haber sido posible una adjudicación directa al erario público, C.10.19.2.2: (Const. 230).

${ }^{55}$ L.E.C. Artículo 670.

${ }^{56}$ Así Ulp. 25 ad ed. D.21.2.50, sobre responsabilidad de los auxiliares del juez por vender a bajo precio, la posibilidad de que, no hallándose comprador que ofreciese un precio digno, se adjudicase al ejecutante (C.8.22.2.1 (Alex. 223) sin que se pudiese reclamar el resto de la deuda (Ulp. 3 de off. cons. D.42.1.15.3) si la cosa subastada estaba previamente pignorada, debería ser el precio superior a la deuda garantizada por la prenda anterior (Ulp. 3 de off. cons. D.42.1.15.5).

${ }^{57}$ Está muy discutido en la Romanística si se su origen es clásico, dioclecianeo, postclásico o, incluso puramente justinianeo. Vid. KASER, M., RPR. I, parág. 130, IV, 2. MAYER-MALI, T., Privatautonomie und Vertragsethik im Digestenrecht, en Iura 6 (1955) (Note e discussioni) págs. 138, TRIANTAPHYLLOPOULOS, J. en Synteleia Arangio-Ruiz, II, Varia Graeco-Romana, 2. Vente romaine classique et "corpus Hippocraticum», págs. 903-904, VISKY, K. Die Proportionalität von Wert und Preis in den römischen Quellen des III Jahrhundert, en RIDA 16(1969), pág. 358, Von LÜBTOW, De iustitia et iure, en ZS 66(1948) pág. 500, D’ORS, DPR, parág. 490, ALBERTARIO, E., Iustum pretium e iusta aestimatio, en BIDR 31(1931), pág 1, GUTIERREZ-ALVIZ ARMARIO, F., "Laesio enormis» (Revisión de Conjunto con una nota sobre la legislación histórica española), en Estudios Jurídicos, Universidad de Sevilla, 1978, págs. 
La subasta puede resultar fallida por falta de postores lo que llevaba, en Derecho Romano a la adjudicación de la misma al ejecutante $^{58}$. La ley de Part. 3.27.6 concluye acogiendo esta posibilidad:

E si acaeciesse que en los veynte dias sobredichos non saliesse comprador que la comprasse por miedo, o por amor del vencido, o por otra razon. Estonce debe el judgador otorgar la al vencedor, por tanto quanto entendiere que vale la cosa.

Surge la duda sobre si esta adjudicación de la cosa al ejecutante, en caso de no hallarse postor, extinguía totalmente la deuda, o bien lo hacía tan sólo hasta donde alcanzase su valor, quedando el ejecutado deudor por el resto. Curiosamente la cuestión cobra candente actualidad en nuestros días, por la crisis económica y la presión social para que las entidades de crédito acepten la llamada «dación en pago. El rescripto de Severo y Caracalla que establece la adjudicación al ejecutante, en caso de subasta fallida, tal como nos lo refiere Ulp. 3 de off. cons. D.42.1.15.3, es tajante en el sentido de si el acreedor prefiriese quedarse las cosas tomadas en prenda, debe contentarse con ellas y no podía pedir más, porque es como si hubiese transigido sobe su crédito.

...si creditor maluerit pignora in creditum possidere isque esse contentus, rescriptum est non posse eum quod amplius sibi debetur

373-407. GARCÍA SÁNCHEZ, J., La laesio enormis y el precio de la subasta, en Actas del II Congreso Iberoamericano de Derecho Romano, Murcia 1997, págs. 75-97, La laesio enormis: del rescripto de Diocleciano (4.44.2) al Código de Comercio hispano de 1829, pasando por Hevia Bolaño, en RIDA 48 (2001), págs.. 91-130, «Naturaliter circumvenire de pretio». La doctrina salmantina del siglo XVIII, en El Derecho Comercial de Roma al Derecho Moderno, Univ. De las Palmas de Gran Canaria, 2007. Paul. 34 ad ed. D.19.2.22.3, Ulp. 11 ad ed. D.4.4.16.4, Herm. 2 iuris epit. D.19.2.23, C.8.22.2.1 (Alex. 223) C.8.40.18 (Phil 244). En la legislación moderna vid. Código civil, español, art. 1291, Código civil italiano, de 1942, art. 1448, Compilación de Derecho civil de Cataluña, Texto Refundido, de 19 de julio de 1984, art. 321 y Fuero Nuevo de Navarra, de 1 de marzo de 1973, Ley 499.

${ }^{58}$ Ulp. 3 de off. cons. D.42.1.15.3: Si pignora, quae capta sunt, emptorem non inveniant, rescriptum est ab imperatore nostro et divo patre eius, ut addicantur ipsi, cui quis condemnatus est, addicantur autem utique ea quantitate quae debetur. nam si creditor maluerit pignora in creditum possidere isque esse contentus, rescriptum est non posse eum quod amplius sibi debetur petere, quia velut pacto transegisse de credito videtur, qui contentus fuit pignora possidere, nec posse eum in quantitatem certam pignora tenere et superfluum petere. Esta solución presenta un claro paralelismo con lo que ocurría en el pignus convencional, en el que mediante la lex commisoria, abolida por Constantino en el 326 (C.Th.3.2.1=C.8.34.3pr.) y, más tarde, la impetratio dominii, adquiría el acreedor pignoraticio insatisfecho la propiedad de la cosa, manifestando su voluntad en este sentido (C.8.33.1, Alex. 229, C.8.33.3 del 530). Vid. FREZZA, P., Op. cit. pág. 230 y sigs., FLEISCHMANN, M. cit. pág. 96, 
petere, quia velut pacto transegisse de credito videtur, qui contentus fuit pignora possidere, nec posse eum in quantitatem certam pignora tenere et superfluum petere.

Así como esta ley de Partidas es muy clara en el caso de que la cosa se vendiese por más o por menos del importe de la deuda del ejecutado, estableciendo que ... si por aventura mas valiesse que la debda que avia a recebir, lo demás debe lo dar al que era señor de la cosa. E si valiesse menos debe el judgador aun, entregar en los bienes del vencido aquello que valia de menos ..., no es tan explícita en el caso de adjudicación al ejecutante por falta de compradores. Pero la expresión del texto según la cual debe el juez otorgar el objeto al vencedor ... por tanto quanto entendiere que vale la cosa, parece abonar la idea de el Rey Sabio rompió, en este punto, con la tradición romana y dispuso que la deuda se extinguiese tan sólo en la medida del valor de la cosa adjudicada. Esta discordancia no pasó inadvertida a Gregorio López, quien en su glosa se pregunta ... an si simpliciter adiudicatio videatur ad iudicata pro toto debito?, remitiéndose a Bártolo y Saliceto. Cabe aún una última precisión en este punto, y es la de quién debía decidir cuánto valía la cosa: parece que el texto permite interpretar que quedaría al arbitrio de juez.

A modo de resumen, a través de este somero estudio, hemos tratado de comprobar cómo las Partidas recogen la regulación impuesta en Derecho Romano a partir de Antonino Pío para la ejecución de sentencias líquidas, reiterando en sus puntos fundamentales los principios que, probablemente, estaban asentados en la práctica forense (tanto en lo que respecta al órgano ejecutor como en el procedimiento y orden para la traba de embargos, la resolución de controversias y la realización de los bienes).

Surgen sin embargo, del análisis de los textos cuestiones en las que el Rey Sabio se aparta de la doctrina romanista. Así encontramos diferencias en cuanto a los plazos (mucho más breves y expeditivos en las Partidas que en el precedente romano), o al hecho de que se hacía al acreedor ejecutante poseedor de los bienes mientras se llevaba a cabo la ejecución, pero también, diferencias con mayor calado, en las consecuencias de la adjudicación del bien al ejecutante, en caso de no encontrarse postores. 